\title{
FTIR spectroscopic investigation of mineral structure of streptozotocin induced diabetic rat femur and tibia
}

\author{
Handan Boyar ${ }^{\mathrm{a}}$, Belma Turan ${ }^{\mathrm{b}}$ and Feride Severcan ${ }^{\mathrm{a}, *}$ \\ ${ }^{a}$ Department of Biology, Middle East Technical University, 06531 Ankara, Turkey \\ ${ }^{\mathrm{b}}$ Department of Biophysics, Ankara University Medicine Faculty, 06100 Ankara, Turkey
}

\begin{abstract}
Diabetes mellitus (DM) can be accepted as a heterogenous multi organ disorder that can affect various systems of the human body. Disorders include retinopathy, neuropathy, cardiomyopathy, musculoskeletal abnormalities such as diminished bone formation and bone healing retardation. Low bone mineral density is often mentioned as a complication for patients with insulin dependent diabetes mellitus (type I DM). Streptozotocin (STZ) induced diabetic rats are good models for investigation of the complications of insulin dependent diabetes. In the present study, the effects of STZ induced diabetes on the mineral environment of rat bones namely femur and tibia were studied by Fourier transform infrared (FTIR) spectroscopic technique. The results revealed that mineral crystal sizes increased and carbonate content decreased for diabetic femur and tibia. These changes can be due to the formation of osteoporosis which is widely seen in diabetic patients.
\end{abstract}

Keywords: Diabetes, FTIR, rat bone, femur, tibia, mineral crystal size

\section{Introduction}

Diabetes mellitus (DM) is associated with an extensive list of complications involving nearly every tissue in the body. Most studies indicate that it is a complication for patients with insulin dependent diabetes mellitus (IDDM, or type I), especially those with poor metabolic control [1]. It was associated with low turnover osteopenia either in the animal model or in type I diabetic children and adolescents [2,3]. On the other hand, in patients with non-insulin dependent diabetes mellitus (NIDDM, or type II) the risk of osteopenia is not clear as in type I diabetes [4]. Conflicting results appear in literature such as the evidence of a decreased, normal or increased skeletal mass [5-7]. In these patients, increased adipose tissue in connection with the frequently seen overweight yields metabolically active steroid hormones and insulin related growth factors that may stimulate bone formation. Clinically, diabetes is often associated with reduced bone mass and delayed fracture healing in humans $[6,8,9]$. Experimentally, diabetes adversely affects the properties of intact bone and impairs fracture healing in rats [10-14]. Impaired bone formation due to a deficit of osteoblasts has been recognised as one of the important factors in the development of diabetic osteopenia $[15,16]$. In matrix part of bone tissue, a decrease in total collagen content and defects in collagen cross-linking have been reported in the fracture callus of STZ induced diabetic rats compared with those in the controls [13,14]. Glucose exposure, either in studies with diabetic animals or in enzymatic studies causes changes in mechanical behaviours of collagenous tissues. These changes are thought to be resulted from the reaction of the glucose to form new cross-links within the structural protein collagen. DM can affect bone formation and resorption by creating several metabolic irregularities in

\footnotetext{
*Corresponding author. Tel.: + 9031221051 66; Fax: + 9031221012 89; E-mail: feride@ @etu.edu.tr.
} 
calcium-phosphate and acid-base balances. Primary disturbances in vitamin D and mineral metabolisms and a deficiency of insulin and IGF-I have been implicated in the pathogenesis of diabetic bone disease in animal models and IDDM patients [1,2,17-19]. On the other hand, free radicals have been shown to be involved in osteoclastogenesis and in bone resorption [20] and it is thought that diabetes mellitus is associated with increased oxidative stress. However, despite a large number of studies, mechanisms of osteopenia or at which extend the bone mineral structure is affected by this disease has not been clarified yet.

In the present study in order to gain structural information about the mineral part of diabetic rat bone tissue, the control and diabetic rat femur and tibia were analysed by Fourier transform infrared (FTIR) spectroscopic technique. This technique has been extensively used to study normal and diseased bones [21-25]. One of the advantages of it lies in the fact that FTIR spectra provide information from all tissue components. For example, the protein and mineral constituents produce intense, structure sensitive IR bands in bone tissues. The percent area of some of the underlying bands in phosphate stretching and bending modes in the spectra of bone samples are used to obtain information about the crystallinity of bone mineral.

\section{Materials and methods}

\subsection{Animals and housing}

Both sex weanling Wistar rats (200-250 g) were divided randomly into two groups as control and diabet (6 per group). They were caged initially at a density of three per cage and as they grew, were then caged individually. They were maintained at an ambient air temperature of $22 \pm 1^{\circ} \mathrm{C}$ and a $12 \mathrm{~h} \mathrm{light} /$ dark cycle. All groups of rats were fed at libitum. Rats were made diabetic by a single intraperitoneal dose of Streptozotocin (STZ) $(50 \mathrm{mg} / \mathrm{kg}$ body weight, Sigma) dissolved in $0.05 \mathrm{M}$ citrate buffer (pH 4.5) and were kept 4-5 weeks. Animals with a plasma glucose level with 2-3 fold of the control were accepted as diabetic. Prior to the experiments the animals were anesthesized with $30 \mathrm{mg} / \mathrm{kg}$ pentobarbital. The femur and tibia, taken from freshly killed animals, were removed from surrounding soft tissue and were stored frozen until FTIR spectroscopic data acquisition.

\subsection{Fourier transform infrared spectroscopic analysis}

The bone samples were ground in a liquid nitrogen-cooled colloid mill (Retsch MM200) and then placed in a vacuum freeze dryer (MAXI dry lyo, Heto). KBr pellets for FTIR study were prepared by mixing the ground bone with $\mathrm{KBr}(1 \mathrm{mg}$ sample/100 $\mathrm{mg} \mathrm{KBr})$ under vacuum. FTIR spectra were recorded in the range of $4000-400 \mathrm{~cm}^{-1}$ on a Bomem MB157 spectrometer purged with dry air. Interferograms were averaged for 400 scans at $4 \mathrm{~cm}^{-1}$ resolution.

GRAMS/32 (Galactic Industries Corporation, Salem, NH, USA) software was used for all FTIR data manipulations. The underlying bands in the $\nu_{1}, \nu_{3} \mathrm{PO}_{4}^{3-}$ stretching region $\left(900-1200 \mathrm{~cm}^{-1}\right)$ were determined upon second derivative analysis. Then, baseline correction and curve-fitting were applied. Band shape was considered as Lorentzian-Gaussian. The process was iterated until a satisfactory fit between the computed and experimental band was obtained. The calculated area of each subband was reported as a percentage. Integrated area function of the same program was used to analyse relative amounts of carbonate and phosphate. For this purpose, in each of the raw spectra of femur and tibia belonging to the animals, the ratio of the integrated area of the $\nu_{2} \mathrm{CO}_{3}^{2-}\left(850-890 \mathrm{~cm}^{-1}\right)$ to the integrated area of the $\nu_{1}$, $\nu_{3} \mathrm{PO}_{4}^{3-}$ absorbance band (900-1200 $\mathrm{cm}^{-1}$ ) was calculated after baseline correction of these peaks [26]. 


\subsection{Statistics}

The results were expressed as mean \pm standard deviation (SD). Data were analysed statistically by using Student's $t$-test and the $p$ values less than 0.05 were considered statistically significant.

\section{Results}

Figure 1 shows a typical FTIR spectrum of a control group rat femur in $1850-450 \mathrm{~cm}^{-1}$ spectral region. As seen from the figure the spectrum is quite complex consisting of several peaks. The bands are labelled on the figure. Rat tibia has similar FTIR spectrum (not shown). The phosphate moiety present in hydroxyapatite gives rise to the peaks in two different spectral regions. The $\mathrm{P}-\mathrm{O}$ symmetric and asymmetric stretching vibrations $\left(\nu_{1}\right.$ and $\left.\nu_{3}\right)$ occur in the $900-1200 \mathrm{~cm}^{-1}$ spectral region as a broad peak whereas, the $\nu_{4}$ asymmetric $\mathrm{P}-\mathrm{O}$ bending vibration gives rise to sharp peaks in $500-660 \mathrm{~cm}^{-1}$ region. Evaluation of changes in the $\nu_{1}$ and $\nu_{3}$ phosphate absorption region is appropriate for monitoring the changes in the crystallinity of the hydroxyapatite phase in bone tissue [24]. Therefore, in the present study only this region was considered to gain information about mineral crystallinity. In this domain, the underlying bands contributing to the baseline-corrected spectra were determined using a combination of second derivative and curve-fit functions. Firstly, by using second derivative arithmetical function, six peaks and their relative peak positions were determined (Fig. 2a). They located at 957, 989, 1020, 1063, 1112 and $1145 \mathrm{~cm}^{-1}$, respectively. Band assignments of these six subbands were given in Table 1 . This information was used as initial parameters for curve-fit analysis of the $\nu_{1}, \nu_{3} \mathrm{PO}_{4}^{3-}$ stretching region (Fig. 2b). The location of the third band at $1020 \mathrm{~cm}^{-1}$ shows that for both of control and diabetic group rat bones, the mineral structure consisted of poorly crystalline nonstoichiometric hydroxyapatite. For

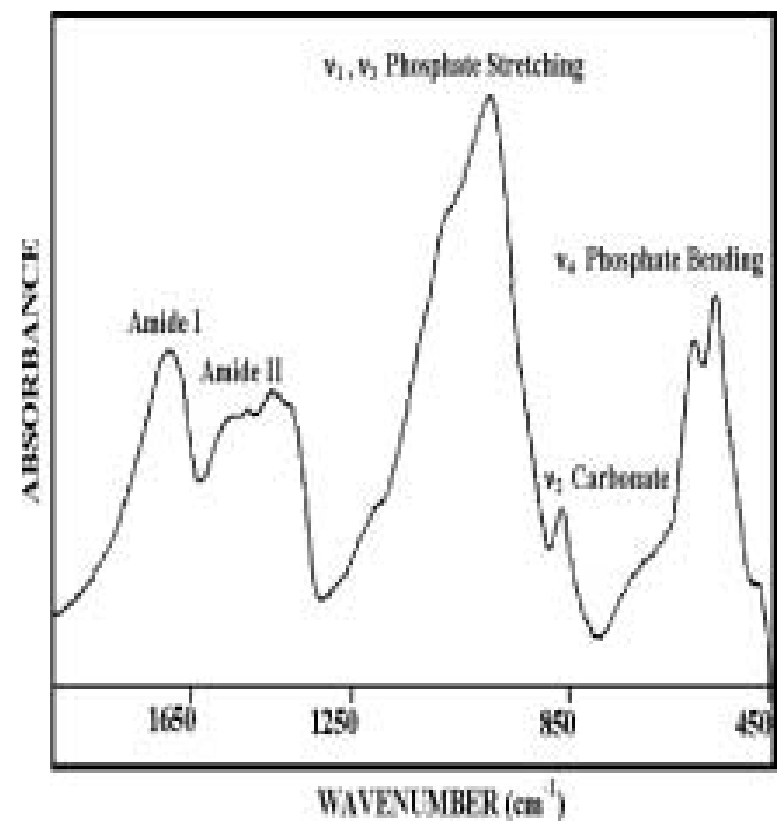

Fig. 1. A typical FTIR spectrum of a normal rat femur in $1850-450 \mathrm{~cm}^{-1}$ spectral region. 


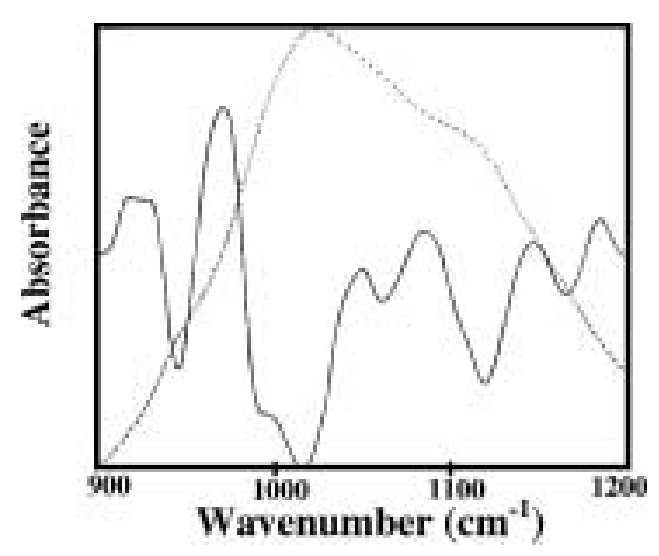

(a)

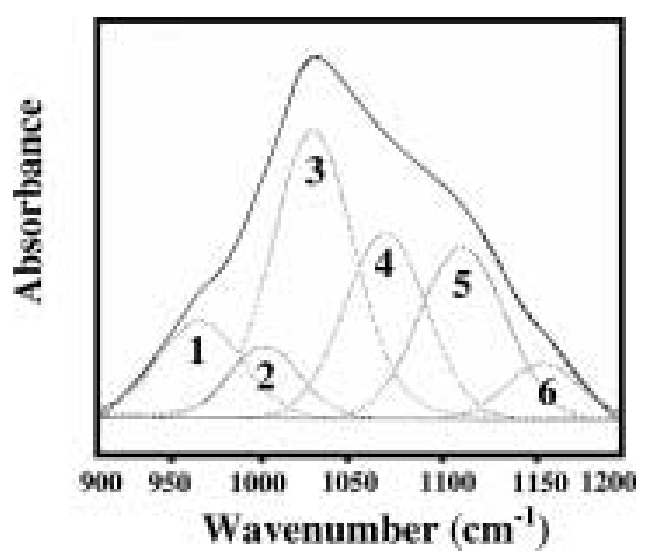

(b)

Fig. 2. (a) Typical FTIR spectrum of a normal rat femur in the $\nu_{1}, \nu_{3}$ phosphate stretching spectral region $(\cdots)$ and its calculated second derivative spectrum (-). (b) The underlying bands as deduced by curve-fit analysis of the same region.

\section{Table 1}

Assignments of subbands obtained from second derivative and curve-fit analysis of $\nu_{1}, \nu_{3} \mathrm{PO}_{4}^{3-}$ stretching region of rat bone spectra

\begin{tabular}{|c|c|c|c|}
\hline $\begin{array}{l}\text { Peak } \\
\text { number }\end{array}$ & $\begin{array}{c}\text { Wavenumber }\left(\mathrm{cm}^{-1}\right) \\
\left( \pm 3 \mathrm{~cm}^{-1}\right)\end{array}$ & Band assignment & Reference \\
\hline 1 & 957 & $\nu_{1} \mathrm{PO}_{4}^{3-}$, poorly crystalline hydroxyapatite $(\mathrm{HA})$ & [24] \\
\hline 2 & 989 & Phosphate in nonapatitic/nonstoichiometric environment & [27] \\
\hline 3 & 1020 & Nonstoichiometric apatites & [27] \\
\hline 4 & 1063 & $\begin{array}{l}\text { Peak resulting from lifting of degeneracy in HA due to symmetry lowering } \\
\text { from } T_{d} \text { in free } \mathrm{PO}_{4}^{3-}\end{array}$ & [27] \\
\hline 5 & 1112 & $\nu_{3} \mathrm{PO}_{4}^{3-}$, poorly crystalline $\mathrm{HA}$ & [24] \\
\hline 6 & $1145-1150$ & Acid phosphate $\left(\mathrm{HPO}_{4}^{2-}\right)$ & [27] \\
\hline
\end{tabular}

femur and tibia of control and diabetic group rats, the curve-fit results expressed as function of underlying band $\%$ area versus peak position were given in Fig. 3a and 3b, respectively. As seen from the figure the mean peak area significantly decreases for the forth peak for diabetic bone tissues. The relative carbonate:phosphate ratio was calculated as the ratio of the integrated area of the peaks of the $\mathrm{CO}_{3}^{2-}$ $\left(850-890 \mathrm{~cm}^{-1}\right)$ and the $\mathrm{PO}_{4}^{3-}\left(900-1200 \mathrm{~cm}^{-1}\right)$ bands. This ratio was calculated as $0.0518 \pm 0.0097$ and $0.0353 \pm 0.0037$ for control and diabetic femur, and as $0.0398 \pm 0.0078$ and $0.0331 \pm 0.0073$ for control and diabetic tibia, respectively. These changes were summarised as a bar diagram in Fig. 4. As seen from the figure the carbonate:phosphate ratio decreases significantly for diabetic femur as compared with control group femur.

\section{Discussion}

The bone mineral is a poorly crystalline, carbonate and acidic phosphate-containing analogue of hydroxyapatite (HA), $\left[\mathrm{Ca}_{10}\left(\mathrm{PO}_{4}\right)_{6}(\mathrm{OH})_{2}\right]$. Although diabetes has been shown, both clinically and experimentally, to affect the properties of intact bone and bone with a healed fracture, changes in mineral properties of diabetic bone tissues have not been well established yet. Mineral features such as carbonate 


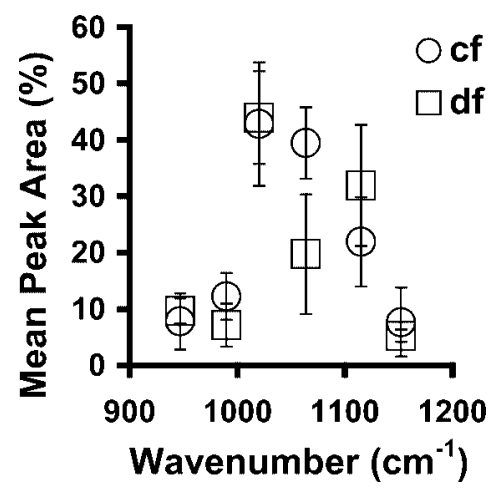

(a)

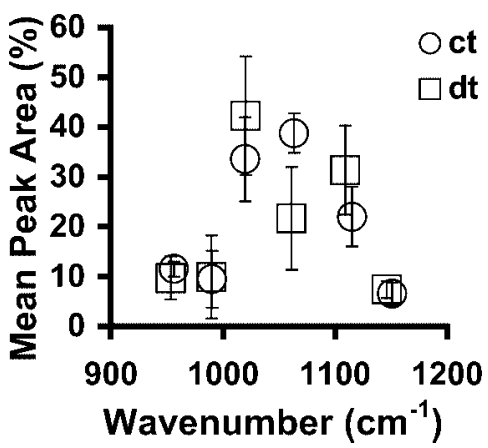

(b)

Fig. 3. (a) The curve-fit analysis results expressed as function of underlying band $\%$ area and spectral position for control (cf) and diabetic femur (df). (b) The curve-fit analysis results expressed as function of underlying band $\%$ area and spectral position for control (ct) and diabetic tibia (dt). Values were shown as mean \pm standard deviation.

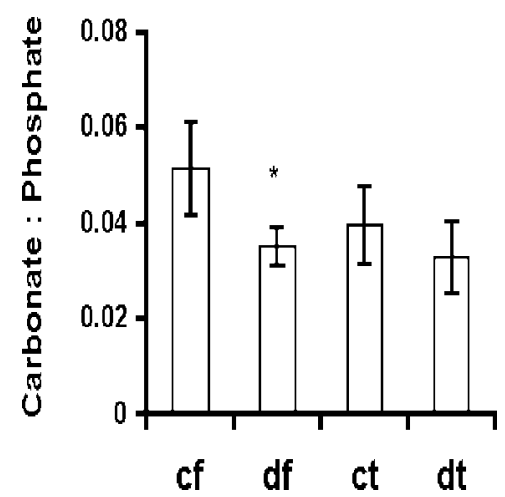

Fig. 4. The variations of carbonate:phosphate ratio for control and diabetic group rat bones. cf: control femur, df: diabet femur, ct: control tibia, dt: diabet tibia. The column height represents the mean values for each group. The error bar indicates the standard deviation where the number of subjects are six in each group. $*$ indicates significant difference with respect to control $(p<0.05)$.

and phosphate content, crystallite size and mineral environment may be altered substantially as a function of tissue type, age and pathology. Therefore, the knowledge of HA crystal size in biological environments provides important insights into the structure of bone and the nature of the deposition and remodelling events that occur in normal and pathological processes [27]. In the present study structural information was obtained about mineral environment of control and diabetic rat bone tissues, by using the combination of second derivative and curve-fit results of the $\nu_{1}, \nu_{3} \mathrm{PO}_{4}^{3-}$ stretching region of the FTIR spectra. We identified the changes in the crystallite sizes of diabetic rat bone mineral. As can be deduced from Fig. 3, there is a significant decrease in the $1063 \mathrm{~cm}^{-1}$ subband of this spectral region in diabetic group. It was previously shown that the percent area of this band is inversely related to the crystal size [24,28]. Thus, in diabetic rat femur and tibia the crystal size increased substantially.

In general, different parts of bone tissue from postmenopausal osteoporotic human subjects exhibited increased crystallinity [29-31]. Similarly, trabecular bone from ovariectomized monkeys contained larger apatite crystals (increased crystallinity) [31]. Osteoporosis defined by clinicians as decreased bone mass, is one of the major causes of death in postmenopausal women and to a lesser extent in men [29] 
due to increased susceptibility to fracture. The texture (i.e. the size, shape and arrangement) of the apatite crystals that comprise the mineral phase of skeletal and dental tissues is a major determinant in establishing the biomechanical properties of these tissues [32,33]. It is thought that electrolytes such as carbonate may be a significant factor in controlling the size of apatite crystals in skeletal tissues by inducing proliferative growth of new crystals [34]. Considering this in mind, the relative carbonate/phosphate ratios were calculated for control and diabetic group rat bones. We found a decrease in the relative amount of carbonate in diabetic rat femur $(p=0.007)$. A similar decrease was also observed for diabetic tibia but in a lesser amount. In a previous study, the carbonate contents of bone apatites of osteoporotic Eskimos were determined to be lower as compared with normal bone [35]. In an other study on ovariectomized rats it was shown that the total carbonate content decreased in trabecular rat bone mineral [25]. Similarly, in a recent study carried out with ovariectomized cynomolgus monkeys, relative amount of carbonate decreased as compared with sham controls in the subchondral and cortical bone regions of proximal tibia [36]. These studies support our present findings. In contrast, in an FTIRM study of lumbar vertebrae from ovariectomized cynomolgus monkeys, the carbonate/phosphate ratio was shown to be higher as compared with the sham controls [31]. This may be due to functional and structural differences in bone tissues taken from different anatomical regions of the same species.

\section{Conclusion}

The present study highlighted the changes in mineral structure and composition of diabetic bone and confirmed that diabetes can cause osteoporosis. Increase in mineral crystal size and decrease in carbonate content are indications of diabetic osteoporosis. Therefore, FTIR spectroscopic technique can be used as a diagnostic tool for investigation of diseased bone tissues and to make comparisons between treated and untreated diseased bones by applying different therapeutic agents.

\section{Acknowledgement}

This work was supported by METU Research Fund AFP-2001-07-02-00-75.

\section{References}

[1] P.S. McNair, Bone mineral metabolism in human type I (insulin dependent) diabetes mellitus, Dan. Med. Bull. 35 (1988), 109-121.

[2] B. Piepkorn, P. Kann, T. Forst, J. Andreas, A. Pfützner and J. Beyer, Bone mineral density and bone metabolism in diabetes mellitus, Horm. Metab. Res. 29 (1997), 584-591.

[3] R. Silberberg, The skeleton in diabetes mellitus: a review of the literature, Diabetes Res. 3 (1986), 329-338.

[4] G. Leidig-Bruckner and R. Ziegler, Diabetes mellitus a risk for osteoporosis?, Experimental and Clinical Endocrinology and Diabetes 109 (Suppl. 2) (2001), S493-S514.

[5] I. Deleeuw and R. Abs, Bone mass and bone density in maturity-type diabetes measured by the ${ }^{125}$ I photon absorption technique, Diabetes 26 (1977), 1130-1135.

[6] M.E. Levin, V.C. Boisseau and L.V. Avioli, Effects of diabetes mellitus on bone mass in juvenile and adult-onset diabetes, N. Engl. J. Med. 294 (1976), 241-245.

[7] M.E. Meema and S. Meema, The relationship of diabetes mellitus and body weight to osteoporosis in elderly females, Can. Med. Ass. J. 96 (1967), 132-139.

[8] L. Cozen, Does diabetes delay fracture healing?, Clin. Orthop. 82 (1972), 134-140.

[9] R.T. Loder, The influence of diabetes mellitus on the healing of closed fractures, Clin. Orthop. 232 (1988), 210-216. 
[10] H. Herbsman, J.C. Powers, A. Hirschman and G.W. Shaftan, Retardation of fracture healing abnormalities, J. Sur. Res. 8 (1968), 424-431.

[11] J.C.H. Hou, R.F. Zernicke and R.J. Barnard, Effects of severe diabetes and insulin on the femoral neck of the immature rat, J. Orthop. Res. 11 (1993), 263-271.

[12] J.R. Funk, J.E. Hale, D. Carmines, H.L. Gooch and S.R. Hurwitz, Biomechanical evaluation of early fracture healing in normal and diabetic rats, J. Orthop. Res. 18 (2000), 126-132.

[13] L.R. Macey, S.M. Kana, S. Jingushi, R.M. Terek, J. Borretos and M.E. Bolander, Defects of early fracture-healing in experimental diabetes, J. Bone Joint Surg. (Am.) 71 (1989), 722-733.

[14] T.A. Einhorn, A.L. Boskey, C.M. Gundberg, V.J. Vigorita and M.M. Beyer, The mineral and mechanical properties of bone in chronic experimental diabetes, J. Orthop. Res. 6 (1988), 317-323.

[15] H. Rico, E.R. Hernandez, J.A. Cabranes and F. Gomez-Castresana, Suggestion of a deficient osteoblastic function in diabetes mellitus. The possible cause of osteopenia in diabetics, Calcif. Tiss. Int. 45 (1989), 71-73.

[16] R. Bouillon, M. Bex, E. Van Herck, J. Laureys, L. Dooms, E. Lesaffre and E. Ravussin, Influence of age, sex, and insulin on osteoblast function: Osteoblast dysfunction in diabetes mellitus, J. Clin. Endocrinol. Metab. 80 (1995), 1194-1202.

[17] H.J. Kissler, G. Hofmann, H. Gepp, R.G. Erben and P.O. Schwille, High insulin and low IGF-I plasma levels following pancreas transplantation in rats. Implications for bone and mineral metabolism, Scand. J. Clin. Lab. Invest. 60 (2000), $175-188$.

[18] M.E. Locatto, M.C. Fernandez, D.A. Caferra and R.C. Puche, The long-term effects of pancreaectomy on the Ca metabolism in the rat, Acta Diabetol. Lat. 20 (1983), 297-302.

[19] R. Bouillon, Diabetic bone disease. Low turnover osteoporosis related to decreased IGF-I production, Verh. K. Acad. Geneeskd Belg. 54 (1992), 365-392.

[20] I.R. Garrett, B.F. Boyce, R.O. Oreffo, L. Bonewald, J. Poser and G.R. Mundy, Oxygen derived free radicals stimulate osteoclastic bone resorption in rodent bone in vitro and in vivo, J. Clin. Invest. 85 (1990), 632-639.

[21] B. Turan, S. Bayarı, C. Balçı, F. Severcan and N. Akkaş, A biomechanical and spectroscopic study of bone from rats with selenium deficiency and toxicity, BioMetals 13 (2000), 113-121.

[22] C. Rey, M. Shimuzu, B. Collins and M.J. Glimcher, Resolution enhanced Fourier transform infrared spectroscopy study of the environment of phosphate ion in the early deposits of a solid phase calcium phosphate in bone and enamel and their evolution with age: 2. Investigations in the $\nu_{3} \mathrm{PO}_{4}$ domain, Calcif. Tiss. Int. 49 (1991), 383-388.

[23] M.A. Walters, Y.C. Leung, N.C. Blumenthal, R.Z. LeGoros and K.A. Konsker, A raman and infrared spectroscopic investigation of biological hydroxyapatite, J. Inorg. Biochem. 39 (1990), 193-200.

[24] N.L. Pleshko, A.L. Boskey and R. Mendelsohn, Novel infrared spectroscopic method for the determination of crystallinity of hydroxyapatite minerals, Biophys. J. 60 (1991), 786-793.

[25] S. Bohic, C. Rey, A. Legrand, H. Sfihi, R. Rohanizadeh, C. Martel, A. Barbier and G. Daculsi, Characterization of the trabecular rat bone mineral: Effect of ovariectomy and bisphosphonate treatment, Bone 26 (2000), 341-348.

[26] N.P. Camacho, W.J. Landis and A.L. Boskey, Mineral changes in a mouse model of osteogenesis imperfecta detected by Fourier transform infrared microspectroscopy, Connect. Tiss. Res. 35 (1996), 259-265.

[27] H. Ou-Yang, E.P. Paschalis, A.L. Boskey and R. Mendelsohn, Two-dimensional vibrational correlation spectroscopy of in vitro hydroxyapatite maturation, Biopolymers (Biospectroscopy) 57 (2000), 129-139.

[28] N.L. Pleshko, A.L. Boskey and R. Mendelsohn, An FT-IR microscopic investigation of the effect of tissue preservation on bone, Calcif. Tiss. Int. 51 (1992), 72-77.

[29] E.P. Paschalis, F. Betts, E. DiCarlo, R. Mendelsohn and A.L. Boskey, FTIR microspectroscopic analysis of human iliac crest biopsies from untreated osteoporotic bone, Calcif. Tiss. Int. 61 (1997), 487-492.

[30] R. Mendelsohn, E.P. Paschalis, P.J. Sherman and A.L. Boskey, IR microscopic imaging of pathological states and fracture healing of bone, Appl. Spectrosc. 54 (2000), 1183-1191.

[31] S.J. Gadaleta, A.L. Boskey, E.P. Paschalis, C. Carlson, F. Menschık, T. Baldini, M. Peterson and C.M. Riminac, A physical, chemical and mechanical study of lumbar vertebrae from normal, ovariectomized and nandrolone decanoate-treated cynomolgus monkeys (Macaca fascicularis), Bone 27 (2000), 541-550.

[32] H.D. Wagner and S. Weiner, On the relationship between the microstructure of bone and its mechanical stiffness, J. Biomechanics 25 (1992), 1311-1320.

[33] V.J. Landis, The strength of a calcified tissue depends in part on the molecular structure and organization of its constituent mineral crystals in their organic matrix, Bone 16 (1995), 533-544.

[34] E.D. Eanes and A.W. Hailer, Anionic effects on the size and shape of apatite crystals grown from physiological solutions, Calcif. Tiss. Int. 66 (2000), 449-455.

[35] D.D. Thompson, A.S. Posner, W.S. Laughlin and N.C. Blumenthal, Comparison of bone apatite in osteoporotic and normal Eskimos, Calcif. Tiss. Int. 35 (1983), 392-393.

[36] R.Y. Huang, L.M. Miller, C.S. Carlson and M.R. Chance, Characterization of bone mineral composition in the proximal tibia of cynomolgus monkeys: Effect of ovariectomy and nandrolone decanoate treatment, Bone 30 (2002), $492-497$. 


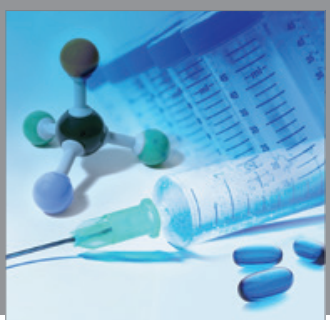

International Journal of

Medicinal Chemistry

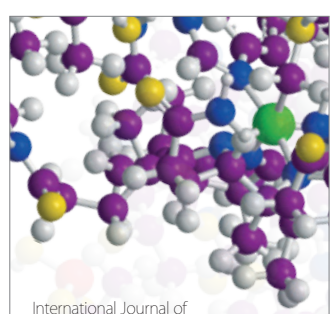

Carbohydrate Chemistry

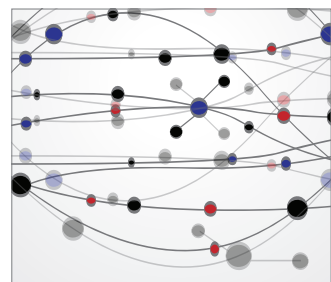

The Scientific World Journal
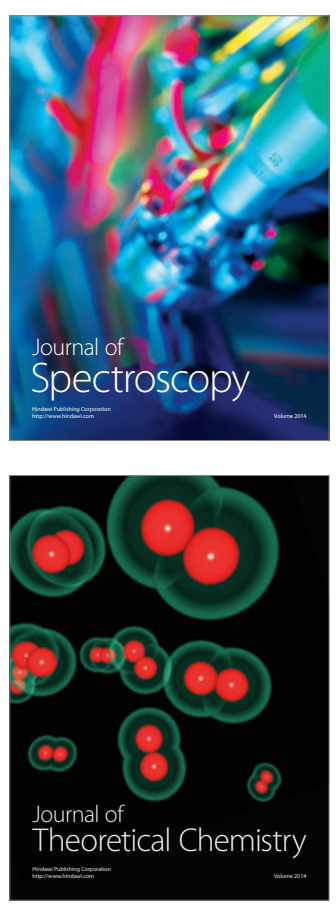
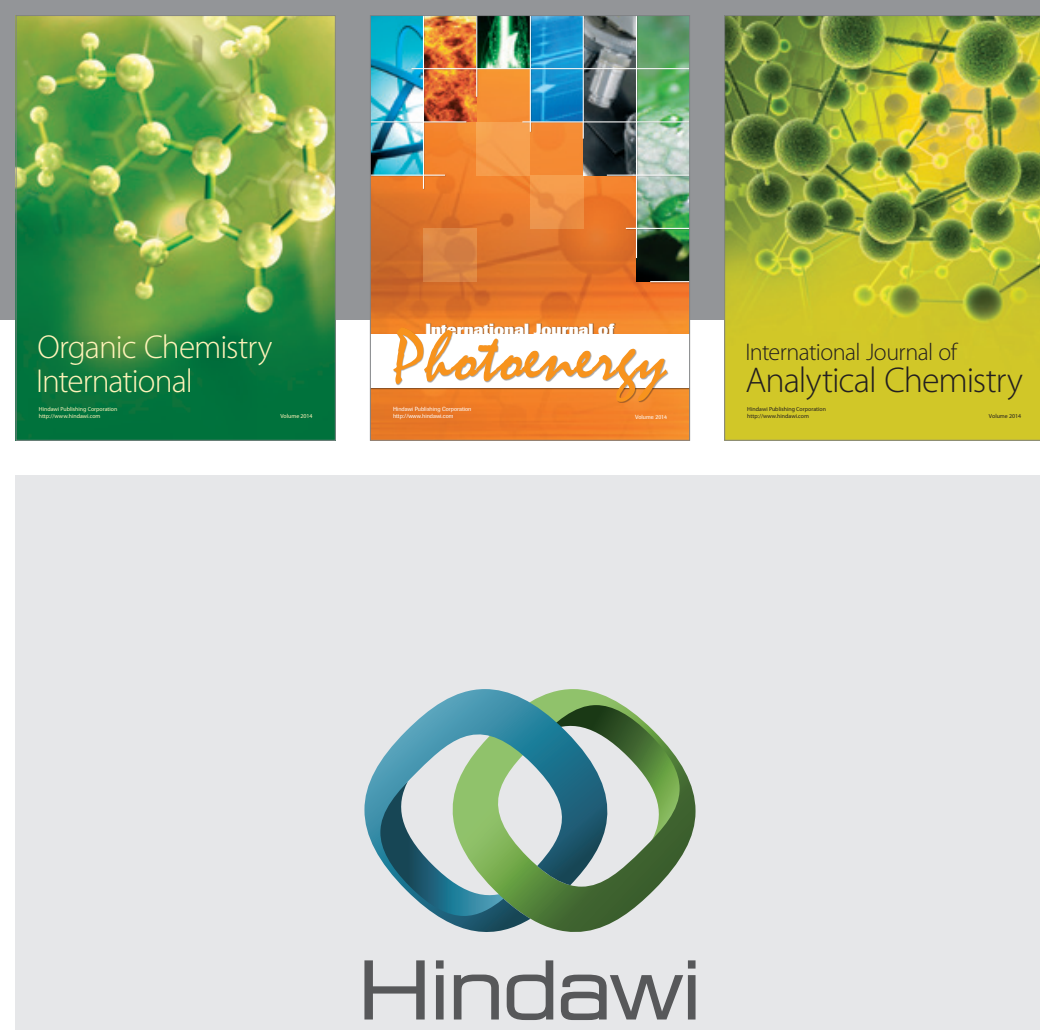

Submit your manuscripts at

http://www.hindawi.com
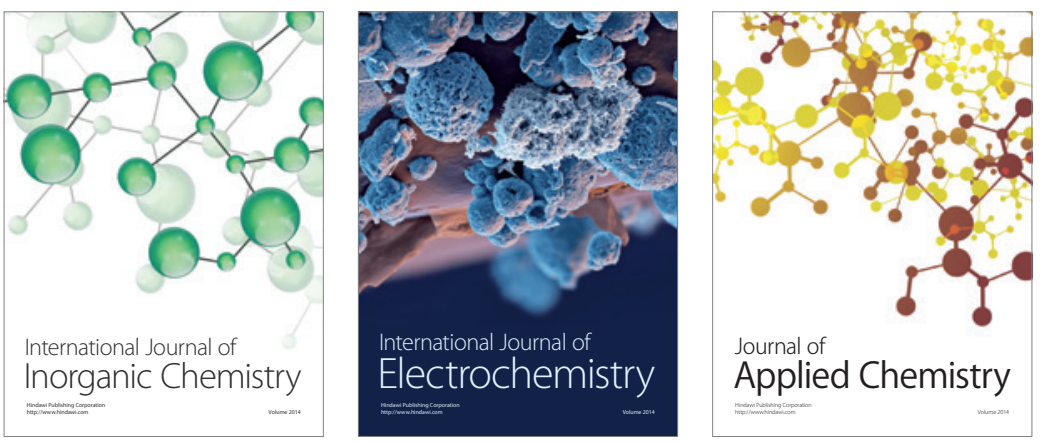

Journal of

Applied Chemistry
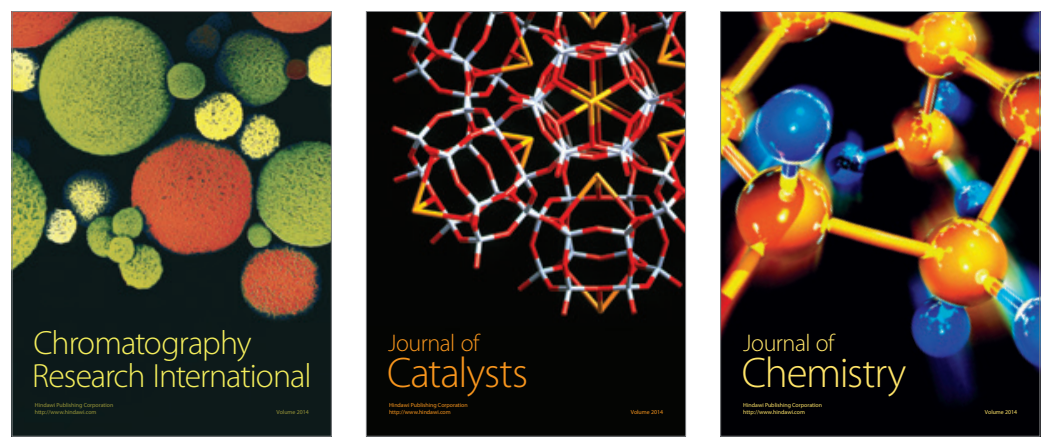
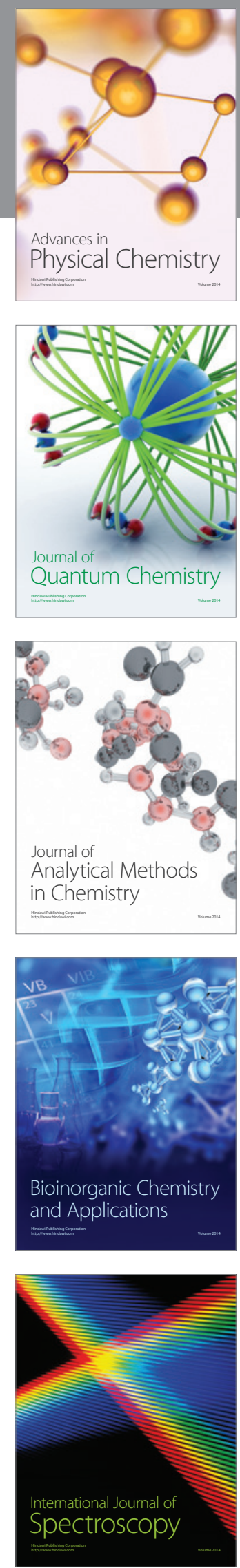